\title{
Retraction
}

\section{Retracted: Enhancing Microstructure and Mechanical Properties of AZ31-MWCNT Nanocomposites through Mechanical Alloying}

\author{
Advances in Materials Science and Engineering \\ Received 7 August 2016; Accepted 7 August 2016 \\ Copyright (C) 2016 Advances in Materials Science and Engineering. This is an open access article distributed under the Creative \\ Commons Attribution License, which permits unrestricted use, distribution, and reproduction in any medium, provided the \\ original work is properly cited.
}

Advances in Materials Science and Engineering has retracted the article titled "Enhancing Microstructure and Mechanical Properties of AZ31-MWCNT Nanocomposites through Mechanical Alloying" [1]. The corresponding author apologizes and the authors agree with retraction. The article was found to contain a substantial amount of material, without citation, from the following published articles:

Figures and Text

(i) Wording in the section "3.1. Microstructure Analysis" and Figure 5 were from Hiroyuki Fukuda, Katsuyoshi Kondoh, Junko Umeda, Bunshi Fugetsu: Interfacial analysis between $\mathrm{Mg}$ matrix and carbon nanotubes in $\mathrm{Mg}-6 \mathrm{wt}$.\% $\mathrm{Al}$ alloy matrix composites reinforced with carbon nanotubes. Composites Science and Technology 2011, Vol. 71(5): 705-709. DOI: 10.1016/j.compscitech.2011.01.015

(ii) Wording in the section "3.1. Microstructure Analysis" and Figure 4 were from M.S. Senthil Saravanan, S.P. Kumaresh Babu, K. Sivaprasad: Mechanically Alloyed Carbon Nanotubes (CNT) Reinforced Nanocrystalline AA 4032: Synthesis and Characterization. Journal of Minerals \& Materials Characterization \& Engineering, Vol. 9, No. 11, pp. 1027-1035, 2010

Text

(iii) C S Goh, J Wei, L C Lee and M Gupta: Development of novel carbon nanotube reinforced magnesium nanocomposites using the powder metallurgy technique. Nanotechnology, Volume 17, Number 1. Published 25 November 2005 (cited in the background, but not in the section "3.2. Mechanical Properties")

(iv) Ahmed Sayed Salim Mohamed: Fabrication and Properties of Carbon Nanotube (CNT) - Reinforced
Aluminium Composites. The American University in Cairo School of Sciences \& Engineering, Spring 2010

Figure

(v) Figure 8(a) was simultaneously published as Figure 1 in J. Jayakumar, B. K. Raghunath, T. H. Rao: Investigation on Fracture Mechanisms in Mg alloy AZ31 Nano Composites Reinforced with Multi Wall Carbon Nano Tubes. International Journal of Innovative Research in Science, Engineering and Technology, Vol. 2, Issue 9, September 2013

\section{References}

[1] J. Jayakumar, B. K. Raghunath, and T. H. Rao, "Enhancing microstructure and mechanical properties of AZ31-MWCNT nanocomposites through mechanical alloying," Advances in Materials Science and Engineering, vol. 2013, Article ID 539027, 6 pages, 2013. 

AZ31-MWCNT Nanocomposites through Mechanical Alloying

\author{
J. Jayakumar, ${ }^{1,2}$ B. K. Raghunath, ${ }^{1}$ and T. H. Rao $^{2}$ \\ ${ }^{1}$ Department of Manufacturing Engineering, Annamalai University, Chidambaram, Tami Nadu, India \\ ${ }^{2}$ Department of Mechanical Engineering, PDVVP College of Engineering, Ahmednagar, Maharashtra, India
}

Correspondence should be addressed to J. Jayakumar; j_j_kumar@rediffmail.com

Received 27 May 2013; Revised 14 September 2013; Accepted 15 September 2013

Academic Editor: Bin Zhang

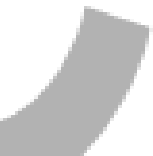

Copyright ( 2013 J. Jayakumar et al. This is an open access article distributed under the Creative Commons Attribution License, which permits unrestricted use, distribution, and reproduction in any medium, provided the original work is properly cited.

\begin{abstract}
Multiwall carbon nanotubes (MWCNTs) reinforced Mg alloy AZ31 nanocomposites were fabricated by mechanical alloying and powder metallurgy technique. The reinforcement material MWCNTs were blended in three weight fractions $(0.33 \%, 0.66 \%$, and $1 \%$ ) with the matrix material AZ31 (Al-3\%, zinc- $1 \%$ rest $\mathrm{Mg}$ ) and blended through mechanical alloying using a high energy planetary ball mill. Specimens of monolithic AZ31 and AZ31-MWCNT composites were fabricated through powder metallurgy technique. The microstructure, density, hardness, porosity, ductility, and tensile properties of monolithic AZ31 and AZ31-MWCNT nano composites were characterized and compared. The characterization reveals significant reduction in CNT (carbon nanoTube) agglomeration and enhancement in microstructure and mechanical properties due to mechanical alloying through ball milling.
\end{abstract}

\section{Introduction}

Mg alloy based MMCs (metal matrix composites) among other MMCs are widely used in various applications in aerospace, automobiles, and sports equipments because of its low density and better mechanical properties [1]. Particulate reinforced $\mathrm{Mg}$ composites are becoming more popular, as compared to fiber reinforced $\mathrm{Mg}$ composites, due to their increased production rate, reduced reinforcement costs and easier fabrication processes. Micrometer-size $\mathrm{SiC}, \mathrm{Al}_{2} \mathrm{O}_{3}$ particles are commonly chosen as a reinforcement in $\mathrm{Mg}$ because of their low cost and easy availability [2]. The microstructure and mechanical properties were significantly improved with the microsize particulate reinforcements and it is reported by various authors that nanosize reinforcement will further improve the properties if the nanoparticles are homogeneously reinforced into the matrix material. Few authors have tried with nano reinforcements like $\mathrm{Al}_{2} \mathrm{O}_{3}$, $\mathrm{SiC}$, and $\mathrm{TiO}_{2}$ and found reasonable improvement in the mechanical properties [3-5]. However, only few attempts have been made so far to reinforce CNTs through mechanical alloying using ball milling into magnesium matrix system which was carried out in this work.
CNTs are the most exciting nanostructured materials of the 20th century with superior mechanical, thermal, and electrical properties discovered by Iijima [6]. CNTs are discovered to have young's modulus and tensile strength in the range of $3 \mathrm{TPa}$ and $2 \mathrm{GPa}$, respectively, and density in the range of $2.0 \mathrm{~g} / \mathrm{cm}^{3}[7,8]$. Looking in to these properties CNTs could be an ideal reinforcement for Magnesium and its alloy as matrix material. Recent researches producing Mg matrix composites reinforced with CNTs has been limited, looking to the problem of agglomeration of CNTs due to Wander wall forces but were largely focused on polymer matrix composites [9-11].

Among the various processes powder metallurgy is the easiest and cheapest method to fabricate the particulate reinforced composites. Goh et al. [2] have developed $\mathrm{Mg}$ $\mathrm{CNT}$ nanocomposites through powder metallurgy route and the results of mechanical behaviour characterization revealed that an increasing volume fraction of CNTs in the magnesium matrix lead to an improvement in $0.2 \%$ YS, ductility, and work of fracture. An increase in the ductility was observed up to $0.18 \mathrm{wt} \%$ of CNTs in $\mathrm{Mg}$, but further increase in amount of CNTs reduces the mechanical properties due to agglomeration of CNTs. 

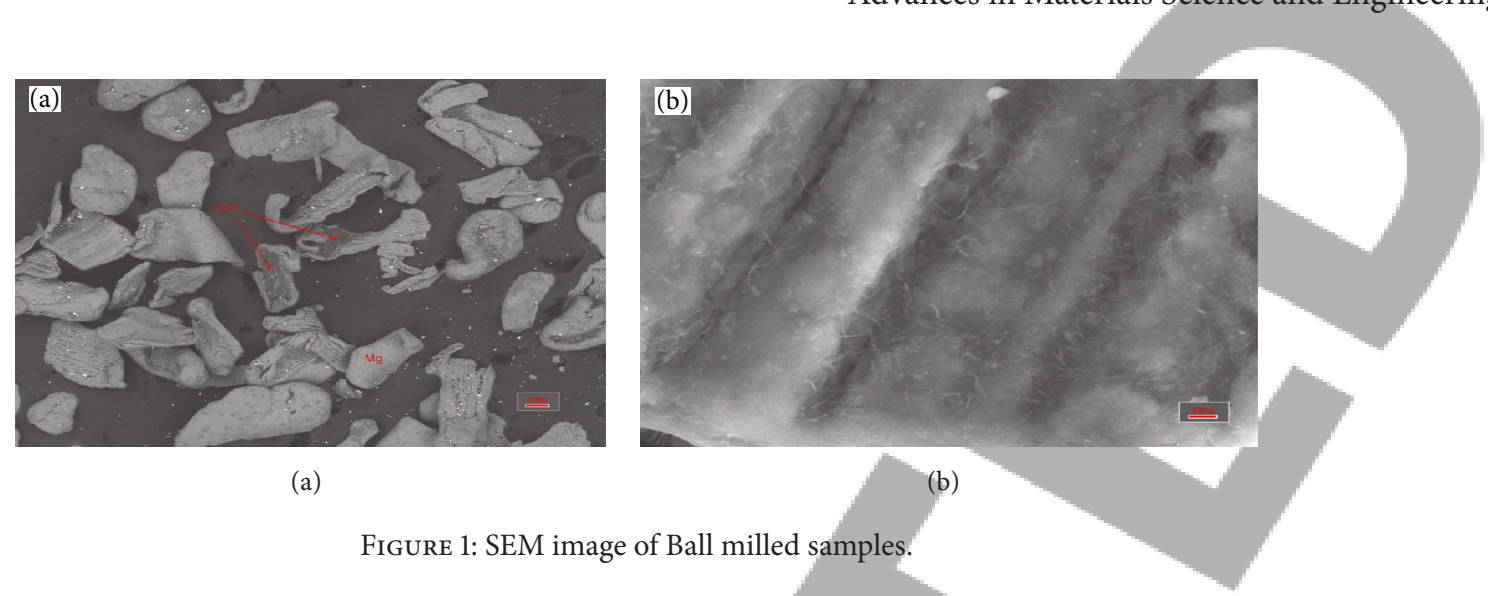

FIGURE 1: SEM image of Ball milled samples.

TABLE 1: Specifications of MWCNT.

\begin{tabular}{lcccccc}
\hline Material & $\begin{array}{c}\text { Diameter } \\
\mathrm{nm}\end{array}$ & $\begin{array}{c}\text { Length } \\
\mu \mathrm{m}\end{array}$ & Purity & Amorphous carbon & $\begin{array}{c}\text { Density } \\
\mathrm{g} / \mathrm{cm}^{3}\end{array}$ & $\begin{array}{c}\text { Surface area } \\
\mathrm{m}^{2} / \mathrm{g}\end{array}$ \\
\hline MWCNT & $20-30$ & $3-8$ & $>95 \%$ & $<3 \%$ & 2.0 & $90-350$ \\
\hline
\end{tabular}

The main objective of this research was to fabricate AZ31 nanocomposites reinforced with higher weight fraction of MWCNTs through mechanical alloying and powder metallurgy process to enhance the mechanical properties. Three weight fractions of MWCNTs $0.33 \%, 0.66 \%$, and $1 \%$ were added to the matrix of AZ31 and blended through high energy planetary ball mill to improve the homogeneity of the reinforcement material and to reduce the agglomeration as reported in the literature [12]. The homogeneity of MWCNTs has been successfully achieved through mechanical alloying process using high energy planetary ball milling. Similar process has not been previously applied on AZ31-MWCNT system and found effective in reinforcing the MWCNTs up to $1 w t \%$ CNTs with reduced agglomeration as reported in the present work. The homogeneously blended powders were then compacted through uniaxial cold compaction and kept in a sealed tubular container to avoid oxidation and sintered. The sintered specimens were then hot extruded using an extrusion die. Similar method was applied to fabricate the specimens of AZ31 without CNTs. The specimens of AZ31 and AZ31-CNT composites were characterized for the microstructure and mechanical properties and compared for the effect of increasing weight fraction of CNTs, mixing medium, cold compaction, sintering temperature, and hot extrusion.

\section{Experimental Details}

Magnesium (Mg) powder with 99.5\% purity, aluminium (Al) and zinc $(\mathrm{Zn})$ powder with $99 \%$ purity supplied by Neeraj Industries, Rohtak, Haryana, India, were used as the matrix material. The MWCNTs produced by Nanoshell (USA), supplied by Intelligent Materials Pvt. Ltd., Chandigarh were used as reinforcement material. The specification of the reinforcement material MWCNTs is given in Table 1.

Powder metallurgy process was used to synthesize both AZ31 alloy and AZ31-CNT composites. The reinforcement material MWCNT with three weight fractions of $0.33 \%$,
$0.66 \%$, and $1 \%$ was added to the matrix of AZ31 alloy and blended through mechanical alloying using a high energy ball mill for $2 \mathrm{~h}$ at a speed of 300 RPM. Tungsten carbide balls were used with ball to powder weight ratio of $1: 15$ and there was no binder or inert gas used during the milling process. The homogeneously blended powders in different variations of CNTs were compacted into cylindrical billets of $30 \mathrm{~mm}$ diameter in a die with a load of 15 tons using a 100 ton hydraulic press under ambient conditions. Monolithic AZ31 alloy billets were also fabricated by the same procedure without CNTs. The compacted specimens of AZ31 and AZ31-CNT were kept in a sealed tubular container to avoid oxidation and sintered at $650^{\circ} \mathrm{C}$ for $2 \mathrm{~h}$ in a tubular sintering furnace. The sintered specimens were then extruded using an extrusion die at $350^{\circ} \mathrm{C}$.

Microstructure investigations of the samples were carried out using SEM (scanning electron microscope), EDS (energy dispersive spectroscope), XRD (X-ray diffraction), and TEM (transmission electron microscope). Density was measured using Archimedean principle at room temperature using Xylene as auxiliary liquid. Porosity was calculated from the theoretical and experimental densities. Hardness was measured using Vickers hardness tester with a load setting of $5 \mathrm{KN}$ and dual time of $15 \mathrm{sec}$. Hardness was measured at 5 places in each sample and the average value was taken. The specimen was polished before the hardness testing. Tensile tests were conducted as per ASTM E8 standard with a specimen size of $5 \mathrm{~mm}$ diameter and $25 \mathrm{~mm}$ gauge length. Ductility was calculated from the elongation during the tensile testing.

\section{Results and Discussion}

3.1. Microstructure Analysis. Mechanical alloying using ball milling technique was effective in dispersing CNTs on the surface of the particles at the beginning of milling, and within the particles after few hours of milling. The microstructures of the ball milled samples are shown in Figure 1. It is observed from the images that during the process of ball 


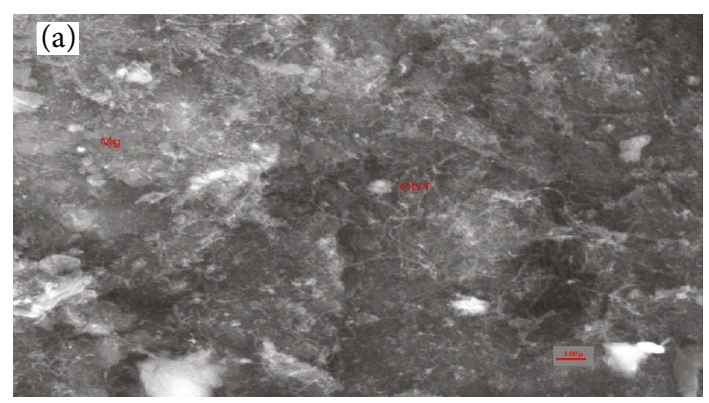

(a)

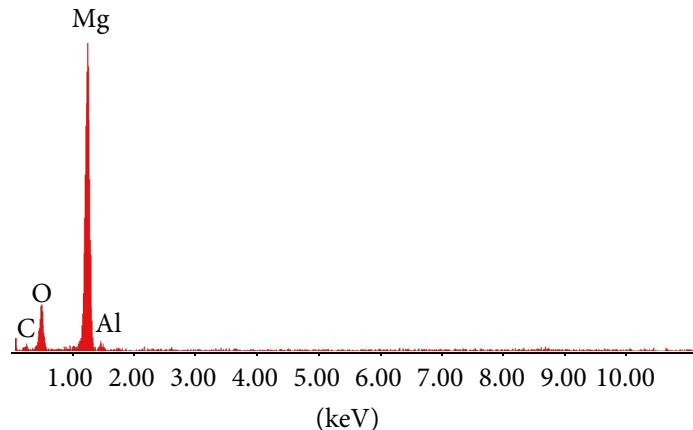

(b)

FIgure 2: SEM and EDS image of AZ31-0.66 wt\% CNT composite sample.

milling the powders collide with the grinding balls creating high pulverization energy responsible for introducing lattice defects that cause the powder particles to deform plastically as shown in Figure 1(a). As the process continues, the powder particles fracture and the reinforcement particles are cold welded to the matrix particles and this occur at the atomic scale. Further milling leads to the enlargement of the forming particles with reinforcement as an intermediate phase appearing inside or at the surface of these particles as shown in Figure 1(b). It is found that the particles are fractured again into submicron matrix particles with fine dispersion of the reinforcement phase. The microstructure and EDS analysis of the AZ31-0.66 wt\% CNT and AZ31$1 \mathrm{wt} \%$ CNT nanocomposites obtained from the extruded samples are shown in Figures 2(a) and 3(a), respectively. The microstructure of sample of $0.66 \mathrm{wt} \% \mathrm{CNTs}$ revealed uniform homogeneity of CNTs in AZ31 matrix; however with $1 \mathrm{wt} \%$ CNT samples agglomerations of CNTs are noticed and has been confirmed through the carbon peaks of EDS image in Figures 2(b) and 3(b), respectively. The EDS images also reveal presence of small amount of $\mathrm{MgO}$ due to oxidation during the ball milling and sintering processes.

The XRD profiles of AZ31-0.66 wt\% CNT ball milled samples taken at every half an hour duration of ball milling are shown in Figure 4. The Peaks of $\mathrm{Mg}, \mathrm{MgO}$ and intermetallic compounds of $\mathrm{Al}_{11} \mathrm{Mg}_{17}$, and $\mathrm{Al}_{2} \mathrm{MgC}_{2}$ were identified in all profiles. It was observed that some of the peaks correspond to the starting materials tend to broaden or disappear with the milling time. The above characteristics may be due to high structural defect during mechanical alloying, dissolution of

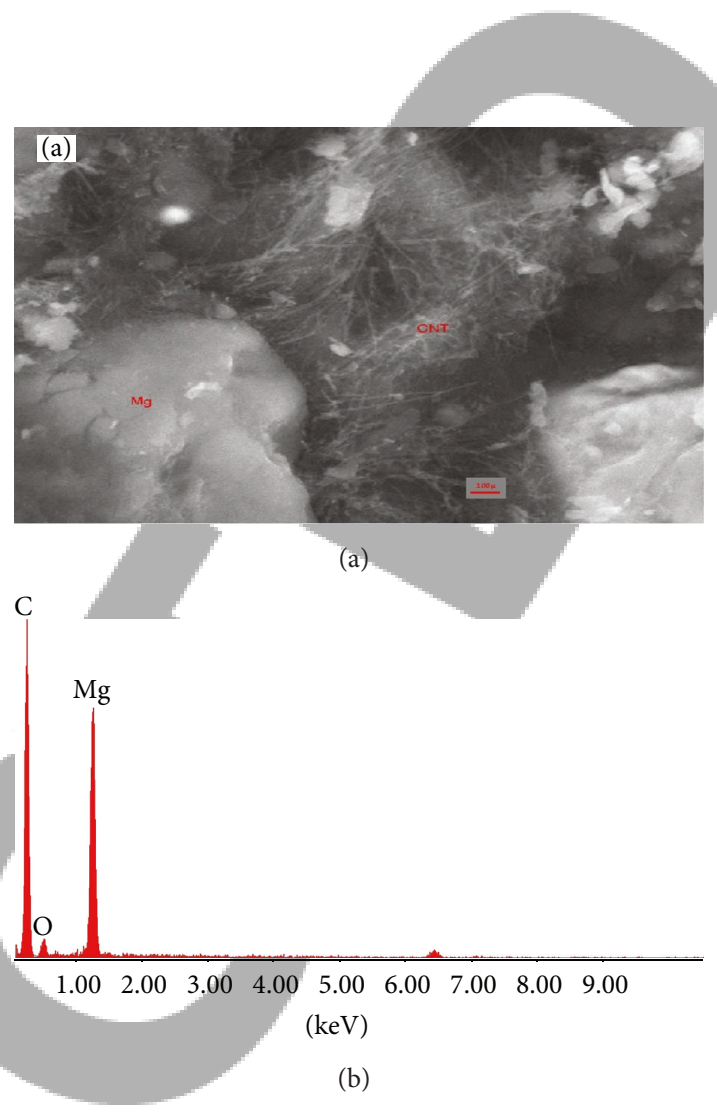

FIGURE 3: SEM and EDS image of AZ31-1wt\% CNT composite sample.

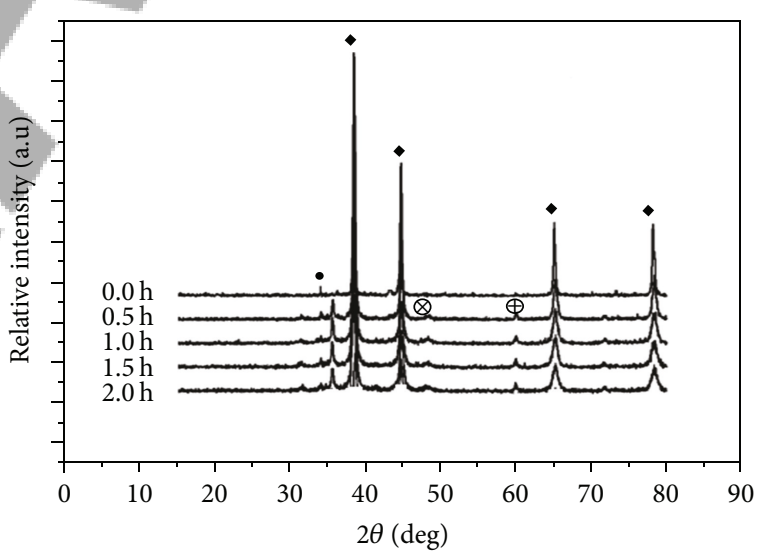

$$
\begin{array}{ll}
\text { - } \mathrm{Mg} & \otimes \mathrm{Al}_{12} \mathrm{Mg}_{17} \\
\text { - } \mathrm{MgO} & \oplus \mathrm{Al}_{2} \mathrm{MgC}_{2}
\end{array}
$$

FIGURE 4: XRD profiles of AZ31-0.66 wt $\%$ CNT ball milled powders.

elemental powders into the matrix, and grain size reduction. The intensity of major element $\mathrm{Mg}$ peak decreases and broadened with milling time. The peak intensities of alloying element start to decrease with respect to milling time which may be due to the partial dissolution of the alloying elements in $\mathrm{Mg}$ lattice. In early stages of milling, lattice parameter decreases with limited variation and increases during 1.5 to $2.0 \mathrm{~h}$ of milling. The peak shift may be due to the reduction in crystallite size of $\mathrm{Mg}$ and increase in the lattice strain induced during mechanical alloying process. The peak intensity of 


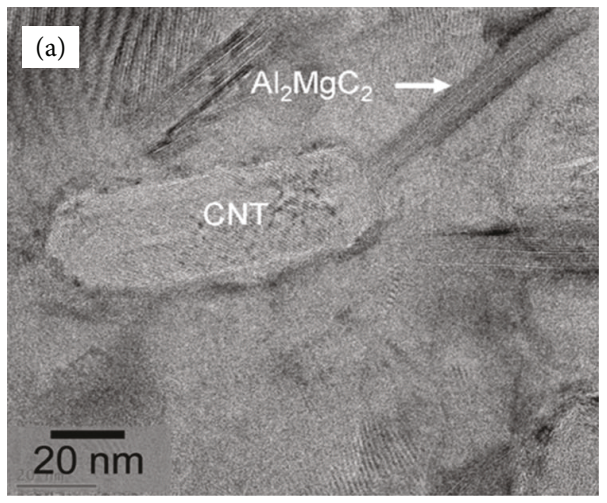

(a)

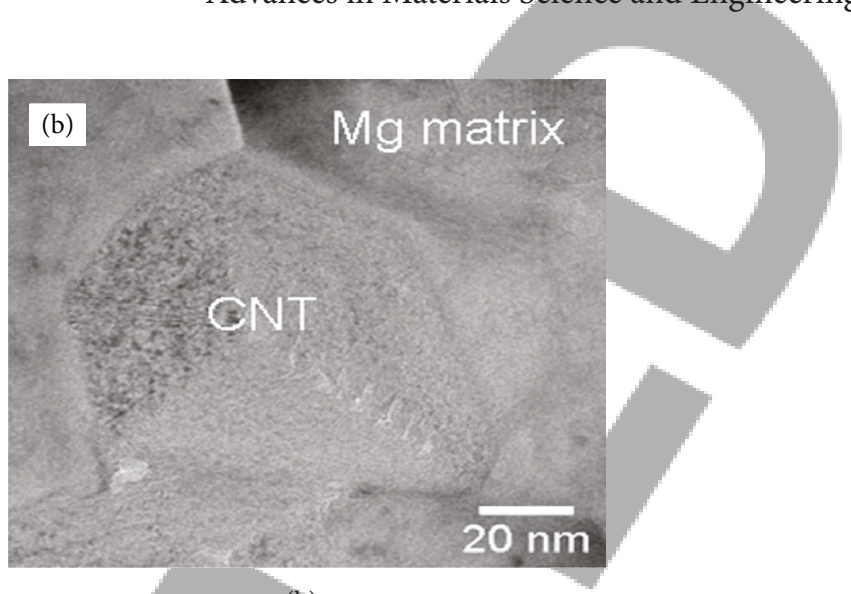

(b)

FIGURE 5: TEM image showing clean interface between Mg matrix and CNTs.

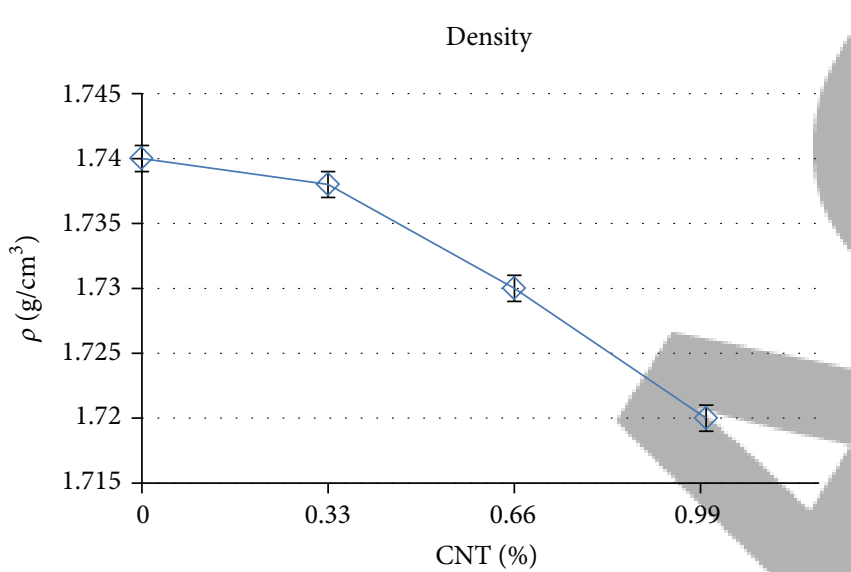

(a)

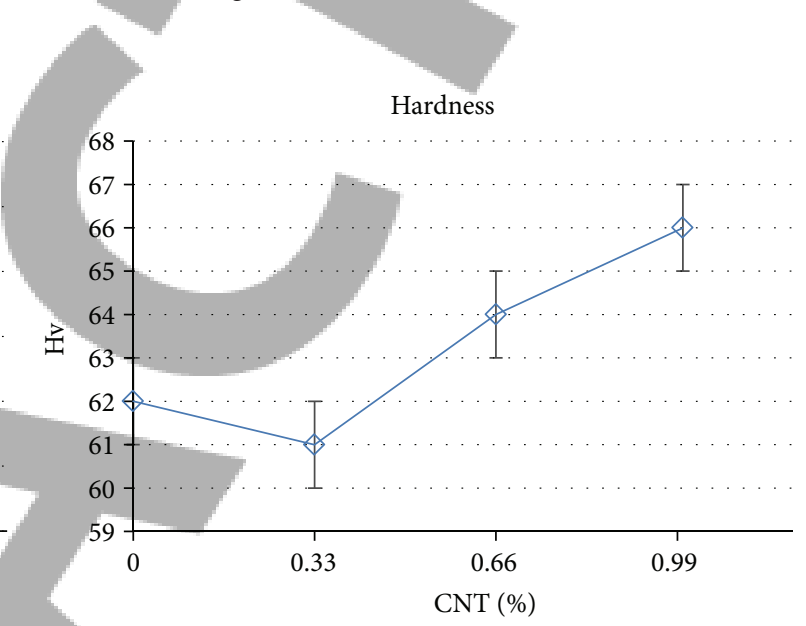

(b)

FIGURE 6: Density and hardness values.

$\mathrm{MgO}$ increases with time due to oxidation and it could be recognized that the identified $\mathrm{MgO}$ at initial stage is originated from the surface oxide film of the as received $\mathrm{Mg}$ raw powders.

The TEM image at the interface between CNT and $\mathrm{Mg}$ matrix of the extruded specimen of the composite is shown in Figure 5. It is observed that a needle-like phase pointed with arrow, obviously different from $\mathrm{Mg}$ matrix projected from not all but some CNT surfaces. Pei et al. reported that $\mathrm{Al}_{2} \mathrm{MgC}_{2}$ was identified as needle-like protrusions directly extended from carbon fibers [13]. The shape of $\mathrm{Al}_{2} \mathrm{MgC}_{2}$ in these references was similar to that produced in the present study and hence, the unknown needle-like phase could be recognized as $\mathrm{Al}_{2} \mathrm{MgC}_{2}$. On the other hand, no other materials or defects were at the interface where no $\mathrm{Al}_{2} \mathrm{MgC}_{2}$ was synthesized and the interface was quite clean. Goh et al. reported the improvement of tensile properties of pure $\mathrm{Mg}$ by $\mathrm{CNT}$ incorporation [2], due to $\mathrm{MgO}$ produced at the interface. This means that even the interface without any materials could provide interfacial strength more or less enough to transfer tensile loading. Hence, the tensile improvement obtained in the present study was due to both the production of $\mathrm{Al}_{2} \mathrm{MgC}_{2}$ and the clean interface between $\mathrm{Mg}$ matrix and CNTs.

3.2. Mechanical Properties. The density and Vickers hardness results of AZ31 alloy and AZ31-CNT nanocomposites are shown in Figure 6. It was observed that the density of the nanocomposites decreases with increasing weight percentages of CNTs. According to observation by Arsenault and Shi [14] during sintering and cooling the distribution of dislocations within the matrix of the composites would not be uniform and there will be higher density near the reinforcing particles. The reason for the decrease in the density is due to the addition of light weight and high volume CNTs compared to the matrix material, which increases the porosity. The porosity level increases in all composites and around 1 vol\% with addition of $1 \mathrm{wt} \% \mathrm{CNTs}$. However the porosity level is within the limit of near net shape products [15]. The hardness of AZ31-CNT nanocomposites reduces by small amount with $0.33 \mathrm{wt} \%$ CNT samples and increases with addition of CNTs. The amount of decrease or increase in the hardness is not found significant to affect the ductility of the material compared to that of AZ31 alloy. Figure 7 shows the 
$0.2 \% \mathrm{YS}$

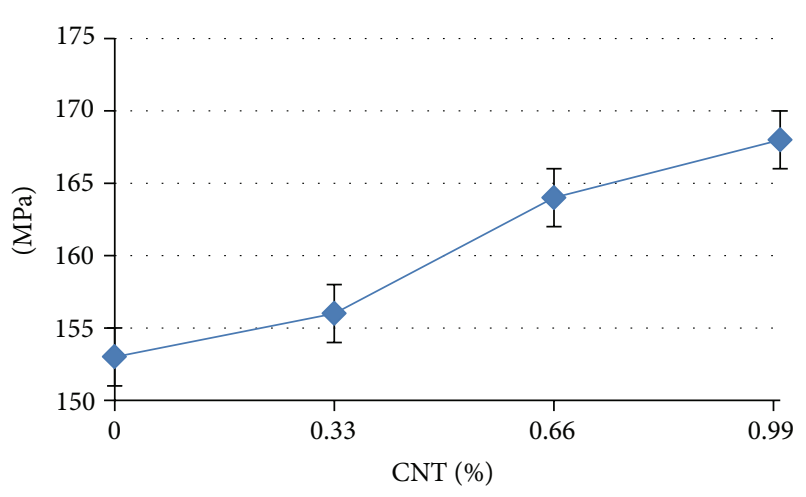

(a)

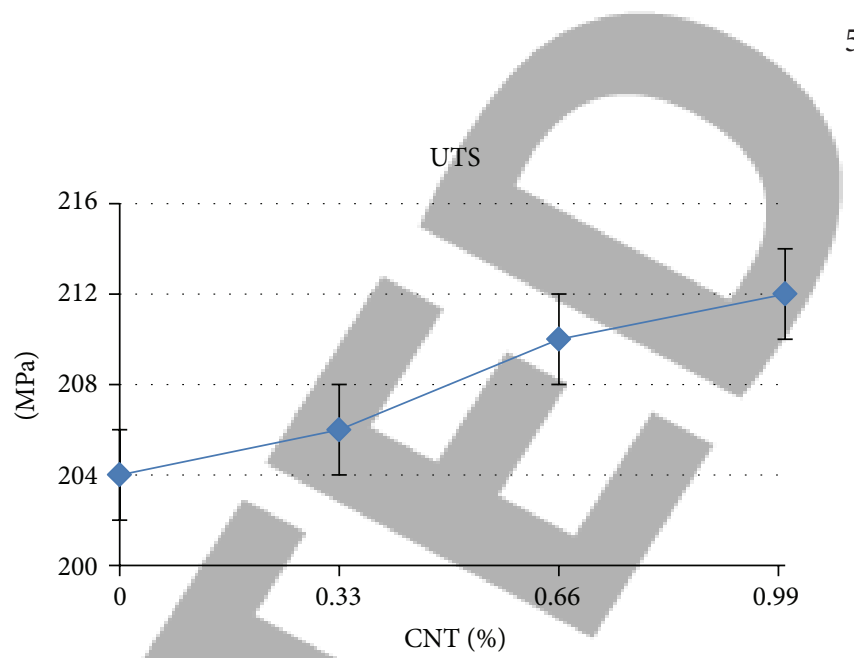

(b)

FIGURE 7: 0.2\% YS and UTS values.

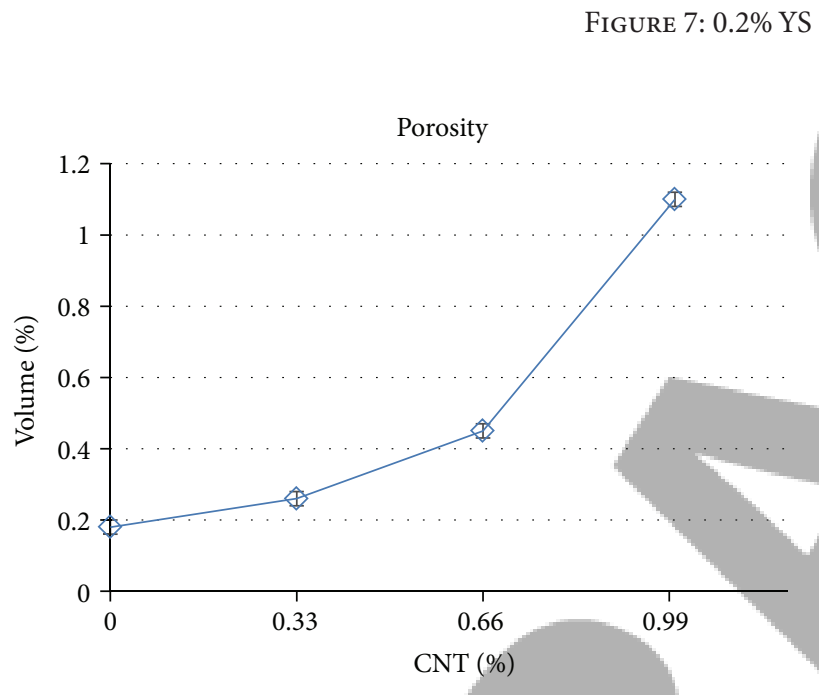

(a)
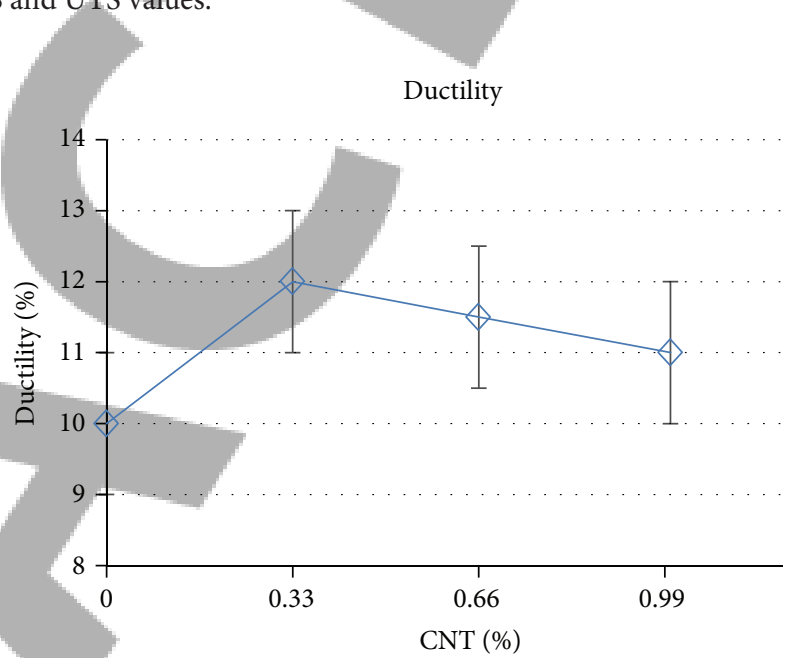

(b)

FIGURE 8: Porosity and ductility values.

tensile behavior of AZ31 and AZ31-CNT nanocomposites. It is observed that there is an increase in $0.2 \%$ YS (yield strength) by $11 \%$ in AZ31-1 wt\% CNT composite compared to monolithic AZ31. The improvement in $0.2 \%$ YS is due to the tubular structure of CNTs, as rod shaped reinforcement strengthen the matrix approximately twice the particle shaped reinforcements of the same volume fraction [16]. UTS (ultimate tensile strength) results of the AZ31-CNT remain relatively unchanged with increasing weight percent of CNTs. Usually when micron-size ceramic or metallic particles are added to $\mathrm{Mg}$ as reinforcements, the UTS of the resultant composites will drop due to particle fracture or particle/matrix interfacial failure. In our case it was found that the CNTs in the matrix remain intact during tensile deformation and due to the high tensile strength and excellent mechanical property of CNTs effectively eliminate the possibility of reinforcement fracture during tensile deformation.

Figure 8 shows the results of porosity and ductility values of the composites. The ductility increases with $0.33 \mathrm{wt} \%$ and start decreases with increase in the amount of CNT to 0.66 and $1.0 \mathrm{wt} \%$. This is due to the fact that $\mathrm{Mg}$ is having a hexagonal close packed (HCP) structure and only possesses three independent easy slip systems, involving the slip of dislocations with $\langle a\rangle$ type burgers vector within the (0001) basal plane. As observed by Agnew and Duygulu [17] in AZ31B alloy, nonbasal slip could be activated at room temperature. Activation of extensive nonbasal (prismatic) cross slip ensures a minimum of five independent slip systems (three from basal and two from prismatic slip systems, resp.) in $\mathrm{Mg}$ which can result in a much higher ductility. Alloying with $\mathrm{Al}$ and $\mathrm{Zn}$ in $\mathrm{Mg}$ may promote nonbasal slip that was not observed in pure Mg. Previous studies have shown that the presence of reinforcements can produce a slip mode transition depending on the reinforcement/particle interaction [18]. Reinforcement with CNTs may lead to an activation of cross slip in nonbasal slip planes responsible for the increased ductility observed in the present study with 0.33 wt $\%$ CNT composites. Ductility starts decreasing when higher percentages of CNTs were added in to the AZ31 matrix. When a relatively larger amount of CNTs is added to the AZ31 matrix, there will be some areas in the matrix where CNTs, with their large surface area, come into contact with 
each other rather than with matrix material, forming small clusters. These clusters will prevent effective bonding between the matrix material and CNTs and lead to minute cracks in the matrix even before tensile testing. These cracks inevitably act as nucleation sites for plastic instability and lead to failure of the material with lower ductility. However, the amount of cracks and porosity in the matrix are still kept within the limit of 1.1 vol.\%, which accounts for only a slight decrease in ductility.

The microstructure and mechanical property characterization of AZ31-CNT nanocomposites reveals that the powder metallurgy technique followed by mechanical alloying can be adopted for their manufacture. The results of the present research shows that there is significant increase in the tensile strength and modulus with increase in the CNT up to $1 \mathrm{wt} \%$ without compromising the ductility $[19,20]$. However the increase in CNT more than $1 \mathrm{wt} \%$ will result in agglomeration/clustering of CNTs and reduce the mechanical properties of the material.

\section{Conclusions}

(1) Powder metallurgy process followed by mechanical alloying was successfully applied to synthesize AZ31CNT nanocomposites.

(2) Mechanical alloying through high energy ball milling helps to improve homogeneous mixing and reduces the agglomeration of CNTs within the AZ31 matrix.

(3) The microhardness and tensile tests have revealed enhanced mechanical properties of AZ31-CNT composites due to the effect of mechanical alloying through ball milling.

(4) The results of the mechanical behavior reveal that an increasing volume fraction up to $1 \mathrm{wt} \%$ CNTs in the AZ31 matrix leads to an improvement in $0.2 \%$ YTS without losing ductility.

\section{Acknowledgments}

The authors thank the in charge and staff of the Manufacturing Lab, CEMAJOR Lab of Annamalai University, Chidambaram, Tamilnadu, India, and Metallurgy and Material testing lab of PDVVP College of Engg., Ahmednagar, Maharashtra, India, for extending cooperation in fabricating and studying the mechanical properties of the materials, respectively. They thank Mr. Kiran Bhotkar of Icon equipments Pvt. Ltd, Mumbai, India, for extending cooperation in analyzing the microstructures of the samples.

\section{References}

[1] M. Y. Zheng, K. Wu, and C. K. Yao, "Effect of interfacial reaction on mechanical behavior of SiCw/AZ91 magnesium matrix composites," Materials Science and Engineering A, vol. 318, no. 1-2, pp. 50-56, 2001.
[2] C. S. Goh, J. Wei, L. C. Lee, and M. Gupta, "Development of novel carbon nanotubes reinforced magnesium nanocomposites using powder metallurgy technique," SIMTech Technical Reports, vol. 9, no. 3, 2008.

[3] S. Seshan, M. Jayamathy, S. V. Kailas, and T. S. Srivatsan, "The tensile behavior of two magnesium alloys reinforced with silicon carbide particulates," Materials Science and Engineering A, vol. 363, no. 1-2, pp. 345-351, 2003.

[4] M. Gupta, M. O. Lai, and D. Saravanaranganathan, "Synthesis, microstructure and properties characterization of disintegrated melt deposited $\mathrm{Mg} / \mathrm{SiC}$ composites," Journal of Materials Science, vol. 35, no. 9, pp. 2155-2165, 2000.

[5] M. Manoharan, S. C. V. Lim, and M. Gupta, "Application of a model for the work hardening behavior to $\mathrm{Mg} / \mathrm{SiC}$ composites synthesized using a fluxless casting process," Materials Science and Engineering A, vol. 333, no. 1-2, pp. 243-249, 2002.

[6] S. Iijima, "Helical microtubules of graphitic carbon," Nature, vol. 354, no. 6348, pp. 56-58, 1991.

[7] M. R. Falvo, G. J. Clary, R. M. Taylor et al., "Bending and buckling of carbon nanotubes under large strain," Nature, vol. 389, no. 6651, pp. 582-584, 1997.

[8] S. Dong and X. Zhang, "Mechanical properties of Cu-based composites reinforced by carbon nanotubes," Transactions of Nonferrous Metals Society of China, vol. 19, pp. 457-461, 1999.

[9] S. R. Dong, J. P. Tu, and X. B. Zhang, "An investigation of the sliding wear behavior of $\mathrm{Cu}$-matrix composite reinforced by carbon nanotubes," Materials Science and Engineering A, vol. 313, no. 1-2, pp. 83-87, 2001.

[10] X. Chen, J. Xia, J. Peng, W. Li, and S. Xie, "Carbon-nanotube metal-matrix composites prepared by electroless plating," Composites Science and Technology, vol. 60, no. 2, pp. 301-306, 2000.

[11] T. Kuzumaki, O. Ujiie, H. Ichinose, and K. Ito, "Mechanical characteristics and preparation of carbon nanotube fiberreinforced Ti composite," Advanced Engineering Materials, vol. 2, no. 7, pp. 416-418, 2000.

[12] P. R. Soni, Mechanical Alloying: Fundamentals and Applications, Cambridge International Science Publishing, 1998.

[13] Z. L. Pei, K. Li, J. Gong, N. L. Shi, E. Elangovan, and C. Sun, "Micro-structural and tensile strength analyses on the magnesium matrix composites reinforced with coated carbon fiber," Journal of Materials Science, vol. 44, no. 15, pp. 4124-4131, 2009.

[14] R. J. Arsenault and N. Shi, "Dislocation generation due to differences between the coefficients of thermal expansion," Materials Science and Engineering, vol. 81, pp. 175-187, 1986.

[15] P. S. Grant, "Spray forming," Progress in Materials Science, vol. 39, no. 4-5, pp. 497-545, 1995.

[16] P. M. Kelly, "The effect of particle shape on dispersion hardening," Scripta Metallurgica, vol. 6, no. 8, pp. 647-656, 1972.

[17] S. R. Agnew and O. Duygulu, "Plastic anisotropy and the role of non-basal slip in magnesium alloy AZ31B," International Journal of Plasticity, vol. 21, no. 6, pp. 1161-1193, 2005.

[18] G. E. Dieter, Mechanical Metallurgy, McGraw-Hill, London, UK, 1988.

[19] S. F. Hassan and M. Gupta, "Development of ductile magnesium composite materials using titanium as reinforcement," Journal of Alloys and Compounds, vol. 345, no. 1-2, pp. 246-251, 2002.

[20] S. F. Hassan and M. Gupta, "Development of high performance magnesium nano-composites using nano- $\mathrm{Al}_{2} \mathrm{O}_{3}$ as reinforcement," Materials Science and Engineering A, vol. 392, no. 1-2, pp. 163-168, 2005. 